\title{
CHFR-Promoter-Methylation Status Is Predictive of Response to Irinotecan-based Systemic Chemotherapy in Advanced Colorectal Cancer
}

\author{
TOSHIAKI HAGIWARA ${ }^{1}$, KIICHI SUGIMOTO ${ }^{1}$, HIROTAKA MOMOSE ${ }^{1}$, TAKAHIRO IRIE $^{1}$, \\ KUMPEI HONJO $^{1}$, YU OKAZAWA ${ }^{1}$, MASAYA KAWAI ${ }^{1}$, SHINGO KAWANO $^{1}$, SHINYA MUNAKATA ${ }^{1}$, \\ MAKOTO TAKAHASHI ${ }^{1}$, YUTAKA KOJIMA ${ }^{1}$, NOBUKO SERIZAWA ${ }^{2}$, AKIHITO NAGAHARA ${ }^{2}$, \\ ROBERT M. HOFFMAN ${ }^{3}$, MALCOLM V. BROCK ${ }^{4}$ and KAZUHIRO SAKAMOTO ${ }^{1}$ \\ ${ }^{1}$ Department of Coloproctological Surgery, Juntendo University Faculty of Medicine, Tokyo, Japan; \\ ${ }^{2}$ Department of Gastroenterology, Juntendo University Faculty of Medicine, Tokyo, Japan; \\ ${ }^{3}$ Department of Surgery, University of California San Diego and AntiCancer Inc, San Diego, CA, U.S.A.; \\ ${ }^{4}$ Department of Surgery, The Sidney Kimmel Comprehensive Cancer Center \\ at the Johns Hopkins University School of Medicine, Baltimore, MD, U.S.A.
}

\begin{abstract}
Background/Aim: We investigated whether promoter methylation of the checkpoint-with-forkhead-andring-finger-domains (CHFR) gene is a predictor of the efficacy of irinotecan-based systemic chemotherapy for advanced colorectal cancer (CRC) patients. Materials and Methods: CHFR-promoter methylation was measured by quantitative methylation-specific PCR (qMSP). The histoculture drug response assay (HDRA) was used in vitro to analyze the correlation between CHFR-promoter methylation and the efficacy of the irinotecan-active-metabolite SN38 in colorectalcancer tissues from 44 CRC patients. CHFR promotermethylation was also analyzed for its correlation with clinical response to irinotecan-based systemic chemotherapy of 49 CRC patients. Results: CHFR-promoter methylation significantly-positively correlated with inhibition of colon cancer by SN38 in the HDRA ( $p=0.002)$. CHFR-promoter methylation also significantly-positively correlated with clinical response to irinotecan-based systemic chemotherapy ( $p=0.04$ for disease control). CHFR-promoter methylation also significantly-positively correlated $(p=0.01)$ with
\end{abstract}

This article is freely accessible online.

Correspondence to: Kiichi Sugimoto, Department of Coloproctological Surgery, Juntendo University Faculty of Medicine, 2-1-1 Hongo, Bunkyo-ku, Tokyo 113-8421, Japan. Tel: +81 338133111, Fax: +81 338130731, e-mail: ksugimo@juntendo.co.jp

Key Words: Advanced colorectal cancer, checkpoint-with-forkheadand-ring-finger-domains (CHFR), DNA-promoter methylation, irinotecan, histoculture drug response assay (HDRA), clinical correlation, biomarker. increased progression-free survival for patients treated with irinotecan-containing FLOFIRI in combination with bevacizumab, the most-frequent regimen in the cohort. Conclusion: Sensitivity of advanced CRC patients to irinotecan-based systemic chemotherapy can be predicted by the extent of CHFR-promoter methylation.

Colorectal cancer (CRC) is the third most-common malignancy and the second-most-frequent cause of cancerrelated mortality worldwide (1). Recent advances in systemic chemotherapy have improved post-operative outcomes in advanced or metastatic CRC $(2,3)$. The current first-line therapies for unresectable $\mathrm{CRC}$ are oxaliplatinum-based and irinotecan-based regimens. The response rates $(\mathrm{RR})$ are approximately $40-60 \%$ for these regimens $(4,5)$, with time to progression (TTP) of 7-8 months and median overall survival (OS) of 14-21 months (6). The two drugs are equivalent in efficacy in this clinical setting (7). Oxaliplatinum causes severe chronic neurotoxicity, which limits the duration of treatment (8). Therefore, irinotecanbased therapy is often preferred for advanced or metastatic CRC. However, there is currently no established biomarker that is predictive of the clinical benefit of irinotecan-based systemic chemotherapy (9).

DNA methylation is altered in human cancer as originally discovered by Hoffman et al. (10). DNA methylation is involved in the development and progression of CRC (11, 12). DNA methylation of tumor-suppressor genes is useful as a prognostic and susceptibility factor to anti-cancer drugs $(13,14)$. Recently, checkpoint-with-fork- head-and-ringfinger-domains (CHFR)-promoter methylation has been suggested to be associated with favorable treatment 
outcomes of irinotecan-based chemotherapy in patients with advanced or metastatic CRC (9). However, the clinical implications of the methylation status of CHFR in advanced or metastatic CRC cases are largely unexplored. In the present report, we correlated CHFR-promoter methylation with the efficacy of irinotecan-based chemotherapy for advanced or metastatic CRC.

\section{Materials and Methods}

Study populations. Methylation analyses were performed on a training cohort of 44 frozen colorectal tumor tissues from patients with CRC who underwent surgery at Juntendo University Hospital between 2017 and 2020. We also established a test cohort, to measure CHFRpromoter methylation data using frozen colorectal-cancer tissues from 49 patients with CRC who were treated with at least six cycles of irinotecan-based systemic chemotherapy for advanced or metastatic CRC at Juntendo University Hospital between 2011 and 2019. Clinical data from each patient were obtained from institutional databases and medical records. All procedures followed were in accordance with the ethical standards of the responsible committees on human experimentation (institutional and national) and with the Helsinki Declaration of 1964 and later versions. Informed consent to be included in the study, or the equivalent, was obtained from all patients. The study was approved by the Institutional Review Board of Juntendo University Hospital (training cohort: IRB No. 17-036; test cohort: IRB N0. 20-097).

Irinotecan-based systemic chemotherapy. The regimen in each case was determined based on a discussion between the physician and patient. Patients were treated with one of the following irinotecancontaining chemotherapy regimens: FOLFIRI [irinotecan $\left(180 \mathrm{mg} / \mathrm{m}^{2}\right.$ i.v.), leucovorin $\left(200 \mathrm{mg} / \mathrm{m}^{2}\right.$ i.v. on day 1$)$, and 5 -fluorouracil (5-FU) (400 $\mathrm{mg} / \mathrm{m}^{2}$ i.v. bolus followed by $2,400 \mathrm{mg} / \mathrm{m}^{2}$ continuous $i . v$. over $46 \mathrm{~h}$ on day 1$)$ every 2 weeks]; XELIRI [irinotecan $\left(200 \mathrm{mg} / \mathrm{m}^{2} i . v\right.$. on day 1) and capecitabine $\left(800 \mathrm{mg} / \mathrm{m}^{2}\right.$ p.o.twice a day for 2 weeks $)$ every 3 weeks]; IRIS [irinotecan $\left(125 \mathrm{mg} / \mathrm{m}^{2} i . v\right.$. on day 1 and 15) and S-1 (40-60 mg p.o. twice a day for 2 weeks) every 4 weeks]; SIR [irinotecan $\left(150 \mathrm{mg} / \mathrm{m}^{2} i . v\right.$. on day 1$)$ and S-1 (40-60 mg p.o. twice a day for 2 weeks) every 3 weeks]; and irinotecan alone [irinotecan $\left(150 \mathrm{mg} / \mathrm{m}^{2}\right.$ i.v. on day 1$)$ every 2 weeks]. At the physician's discretion, bevacizumab $(5 \mathrm{mg} / \mathrm{kg}$ i.v. on day 1 of each cycle of FOLFIRI or $7.5 \mathrm{mg} / \mathrm{kg} i . v$. on day 1 of each cycle of XELIRI or 5 $\mathrm{mg} / \mathrm{kg} i . v$. on day 1 and day 15 of each cycle of IRIS or $7.5 \mathrm{mg} / \mathrm{kg}$ i.v. on day 1 of each cycle of SIR), or ramucirumab $(8 \mathrm{mg} / \mathrm{kg} i . v$. on day 1 of each cycle of FOLFIRI) or cetuximab (weekly dosage: initial dose: $400 \mathrm{mg} / \mathrm{m}^{2}$ i.v., subsequent doses: $250 \mathrm{mg} / \mathrm{m}^{2} /$ week; biweekly dosage: initial and subsequent doses: $500 \mathrm{mg} / \mathrm{m}^{2} i . v$. on day 1 of each cycle of FOLFIRI and day 8 , cetuximab only) or panitumumab (6 $\mathrm{mg} / \mathrm{kg}$ i.v. on day 1 of each cycle of FOLFIRI or irinotecan) were administered. Changes in tumor burden were assessed using the revised RECIST guidelines (version 1.1) (15).

Clinico-pathological analyses. All specimens were examined in the following manner (16): After resection of the colon and rectum, the excised specimen was cut open by the surgeon. Following formalin fixation, the specimen, lymph nodes and metastatic lesions were examined by a pathologist and clinico-pathological factors [i.e., age, sex (male/female), location of primary tumor (colon/rectum or right side: cecum, ascending colon, transverse colon; leftside:/descending colon), sigmoid colon, rectosigmoid colon, rectum, pre-operative serum carcinoembryonic antigen (CEA), maximum diameter of primary tumor, differentiation of primary tumor, T-classification, N-classification, metastatic sites, TNM stage (17)] were recorded.

Histoculture drug response assay (HDRA). The HDRA was invented by Hoffman et al. (18). The HDRA chemosensitivity results have been previously correlated to clinical outcome, including CRC (19, $20)$. The HDRA was performed as described previously $(20,21)$. Cancer tissues from excised specimens were immediately washed with Hank's balanced salt solution (HBSS), and divided into pieces of about $10 \mathrm{mg}$. These tissue fragments were placed on Gelfoam ${ }^{\circledR}$ (Health Design, Rochester, NY, USA) in 24-well plates and incubated for 7 days in RPMI 1640 medium (GIBCO; Thermo Fisher Scientific, Inc., Waltham, MA, USA) supplemented with $20 \%$ fetal calf serum (GIBCO; Thermo Fisher Scientific, Inc.) at $37^{\circ} \mathrm{C}$ in a humidified atmosphere containing $95 \%$ air $/ 5 \% \mathrm{CO}_{2}$. Preliminary determination of $\mathrm{IC}_{50}$ values (the concentration required for $50 \%$ growth inhibition) indicated $300 \mu \mathrm{g} / \mathrm{ml}$ for 5 -FU and 0.4 $\mu \mathrm{g} / \mathrm{ml}$ for SN38 (a topoisomerase I inhibitor that is the active metabolite of irinotecan). Following histoculture, HBSS $(100 \mu \mathrm{l})$ containing $0.1 \mathrm{mg} / \mathrm{ml}$ type I collagenase (Sigma-Aldrich; Merck $\mathrm{KGaA}$, Darmstadt, Germany) and MTT solution ( $2 \mathrm{mg} / \mathrm{ml}, 100 \mu \mathrm{l})$ were added to each well, and the mixture was incubated at $37^{\circ} \mathrm{C}$ for another $16 \mathrm{~h}$. Following extraction with dimethyl sulfoxide (DMSO), the absorbance in each well was measured with a microplate reader at $540 \mathrm{~nm}$. The mean absorbance from four parallel culture wells was used to calculate the absorbance per gram of cultured tumor tissue. The tumor-tissue weight was determined prior to culture. The inhibition rate (IR) was calculated as: IR=(1$\mathrm{T} / \mathrm{C}) \times 100 \%$, where $\mathrm{T}$ and $\mathrm{C}$ are the mean absorbances of the treated tumor/weight and control tumor/weight, respectively.

Genomic DNA extraction and bisulfite treatment. Genomic DNA was purified from fresh-frozen samples with an AllPrep DNA/RNA Mini Kit (Qiagen, Germantown, MD, USA). A sample (500 ng) of this DNA was bisulfite-converted using reagents contained in the EZ DNA Methylation Kit (Zymo Research, Irvine, CA, USA) and samples were processed according to the manufacturer's instructions.

Quantitative methylation-specific PCR ( $M M S P$ ). The methylation status of the CHFR-promoter region was subjected to qMSP analysis, as follows. Bisulfite-modified DNA was used as a template for fluorescence-based real-time PCR. qMSP was performed using an ABI StepOnePlus Real-Time PCR System (Applied BioSystems, Waltham, MA, USA). CHFR-promoter methylation was examined using a $200 \mathrm{nM}$ forward primer, $200 \mathrm{nM}$ reverse primer and $80 \mathrm{nM}$ probes, with cycling conditions of $95^{\circ} \mathrm{C}$ for $5 \mathrm{~min}$, followed by 55 cycles of $95^{\circ} \mathrm{C}$ for $15 \mathrm{~s}, 60^{\circ} \mathrm{C}$ for $1 \mathrm{~min}$, and $72^{\circ} \mathrm{C}$ for $1 \mathrm{~min}$. The master mix contained $16.6 \mathrm{mM}\left(\mathrm{NH}_{4}\right)_{2} \mathrm{SO}_{4}, 67 \mathrm{mM}$ Tris $\mathrm{pH} 8.8,10$ $\mathrm{mM} \beta$-mercaptoethanol, $10 \mathrm{nM}$ fluorescein, $0.166 \mathrm{mM}$ of each deoxynucleotide triphosphate (dNTP) and $0.04 \mathrm{U} / \mu \mathrm{l}$ of Platinum Taq polymerase (ThermoFisher Scientific). Each assay had a final reaction volume of $25 \mu \mathrm{l}$. Human-female Jurkat genomic DNA treated with CpG Methylase (M.SssI) (New England Bio Labs, Ipswich, MA, USA) was used as a positive methylation-control. Due to low levels of DNA methylation, replicates for some samples 
A

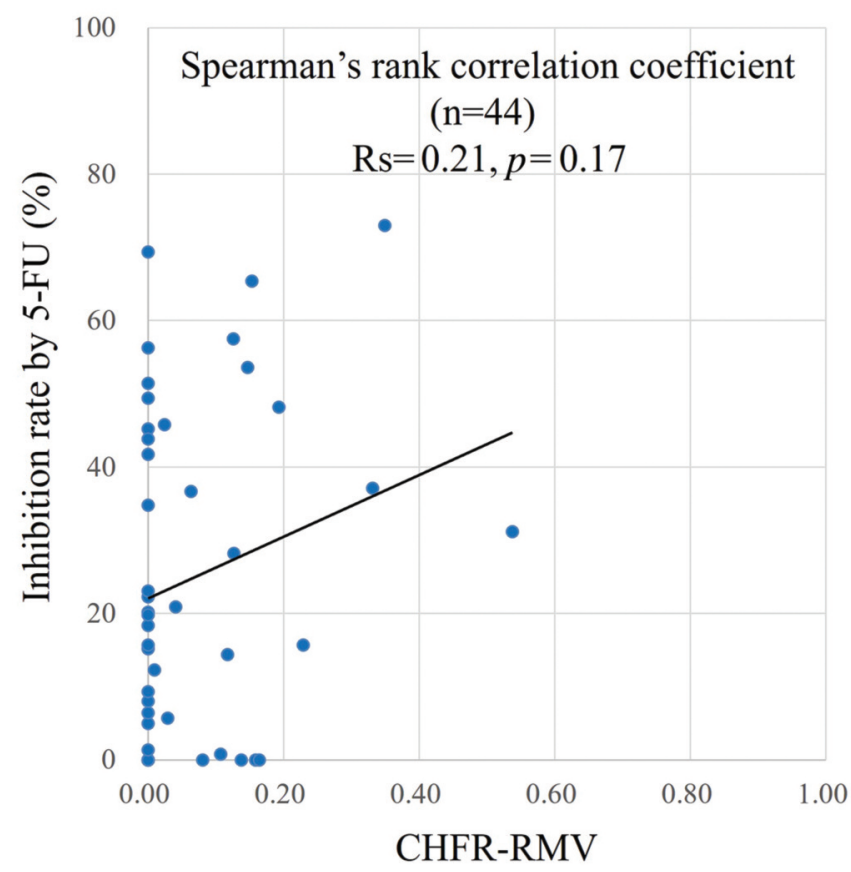

B

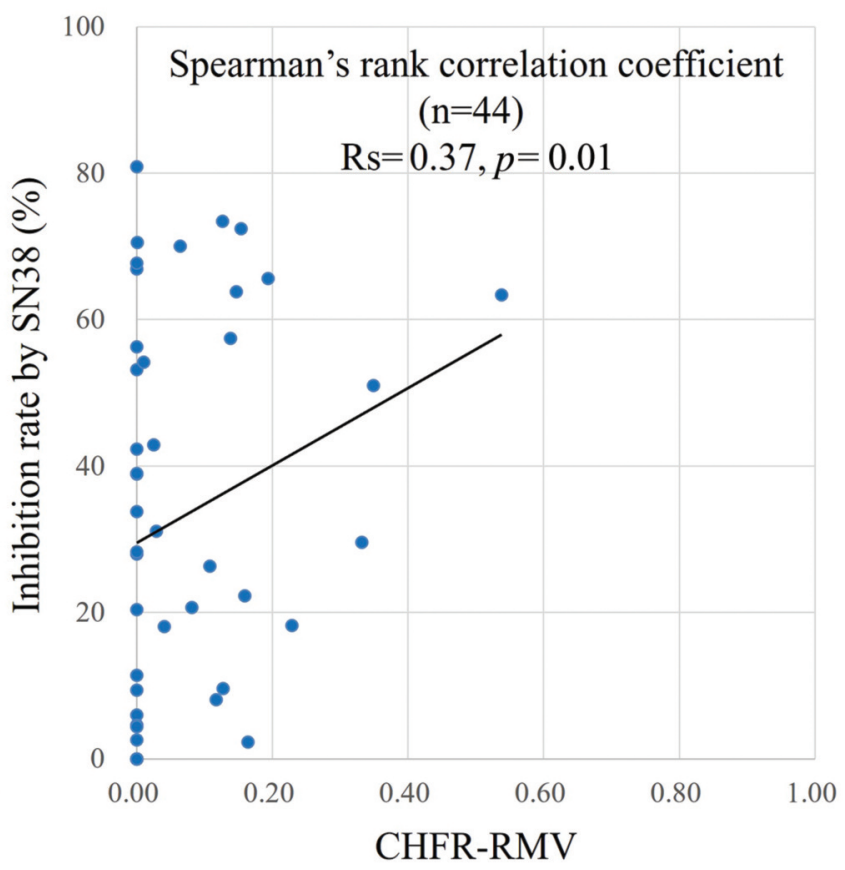

Figure 1. Correlation of efficacy in the HDRA and CHFR-RMV in the training cohort. (A) CHFR-RMV did not show significant correlation with 5FU-induced inhibition $(R s=0.21, p=0.17)$. (B) CHFR-RMV was significantly correlated with inhibition by SN38 $(R s=0.37, p=0.01)$. CHFR: Checkpoint-with-forkhead-and-ring-finger domains; HDRA: histoculture drug response assay; RMV: relative methylation value.

had no detectable methylation, as anticipated. Methylation was quantified using the Relative Methylation Value (RMV), based on calculation of $2^{-\Delta \Delta \mathrm{Ct}}$ for each detectable replicate compared to the mean $\mathrm{Ct}$ for $\beta$-actin (ACTB) $(22,23)$. The bisulfite-modified DNA was assessed for CHFR-promoter methylation with $200 \mathrm{nM}$ forward primer, 5'-GTT ATT TTC GTG ATT CGT AGG CGA C-3', 200 nM reverse primer, 5'-CGA AAC CGA AAA TAA CCC GCG-3', and $80 \mathrm{nM}$ probe, 5'-156-FAM $\backslash$ CGC TCG ACC $\backslash Z$ ZEN $\backslash$ ATC TTT AAT CCT AAC CAA ACG ACT TC \3IABkFQ\-3'. The sequences for beta-actin (ACTB) recognizing both methylated and unmethylated templates were: $200 \mathrm{nM}$ forward primer, 5'-TAG GGA GTA TAT AGG TTG GGG AAG TT-3', 200 nM reverse primer, 5'-AAC ACA CAA TAA CAA ACA CAA ATT CAC-3', and $80 \mathrm{nM}$ probe, 5'156-FAM $\$ TGT GGG GTG \ZEN \GTG ATG GAG GAG GTT TAG '3IABkFQ\-3'. For non-detectable replicates, a Ct of 100 was used to give a near zero value for $2^{-\Delta \Delta \mathrm{Ct}}$. The mean $2^{-\Delta \Delta \mathrm{Ct}}$ value (RMV) was calculated as: mean $2^{-\Delta \Delta \mathrm{Ct}}$ (RMV) $=\left(2^{-}\right.$

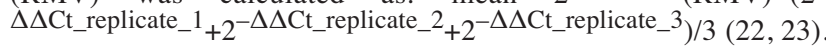

RNA extraction and real-time quantitative PCR (RT-PCR). RNA expression was investigated in 90 patients (training cohort: 44 patients; test cohort: 46 patients) with cancer tissue of sufficient quality to analyze RNA expression. RNA was extracted using an AllPrep DNA/RNA Mini Kit (Qiagen). RNA samples (1,000 ng) were reverse-transcribed into cDNA using a High-Capacity cDNA Reverse Transcription Kit with RNase Inhibitor (ThermoFisher Scientific). cDNA was suspended in TE buffer. RT-PCR was performed on an ABI StepOnePlus Real-Time PCR System (Applied BioSystems). Each PCR contained $4 \mu \mathrm{l}$ of cDNA product, $10 \mu \mathrm{l}$ of PowerUp SYBR Green Master Mix (ThermoFisher Scientific), $1 \mu \mathrm{l}$ of forward and reverse primers combined, made up to a total volume of $20 \mu \mathrm{l}$ with sterile water. Following initial incubation at $95^{\circ} \mathrm{C}$ for $5 \mathrm{~min}$, quantitative RT-PCR amplification was performed using 40 denaturing cycles of $30 \mathrm{~s}$ at $95^{\circ} \mathrm{C}, 30 \mathrm{~s}$ annealing at $55^{\circ} \mathrm{C}$, and $30 \mathrm{~s}$ extension at $72^{\circ} \mathrm{C}$. These experiments were performed in triplicate and the mean value was calculated. The sample value was determined as the $C H F R$ gene/ACTB values. The forward primer for the CHFR gene was GGCAACCAG AGGTTTGACAT and reverse primer was AGTCAGGACGG GATGTTACG. Primers for ACTB were: forward: TTCTA-CAATGA GCTGCGTGTG and reverse: GGGGTGTTGAAGGTCTCAAA.

Statistical analysis. A Fisher Exact probability test was used to compare discrete variables. Continuous variables were compared by the Mann-Whitney $U$-test for individual comparisons and the Wilcoxon signed rank test for paired comparisons. The cumulativesurvival rate was calculated using the Kaplan-Meier method and univariate analyses were performed by the log-rank test. A Cox proportional-hazard regression model was used with the hazard ratio (HR). The cut-off value for RMV was determined using a receiver operating characteristic (ROC) curve, as the value that gave the largest area under the curve (AUC). Data were analyzed using JMP 14 (SAS Institute Inc., Cary, NC, USA). Differences were considered significant at $p \leq 0.05$. Values are expressed as median (range). 


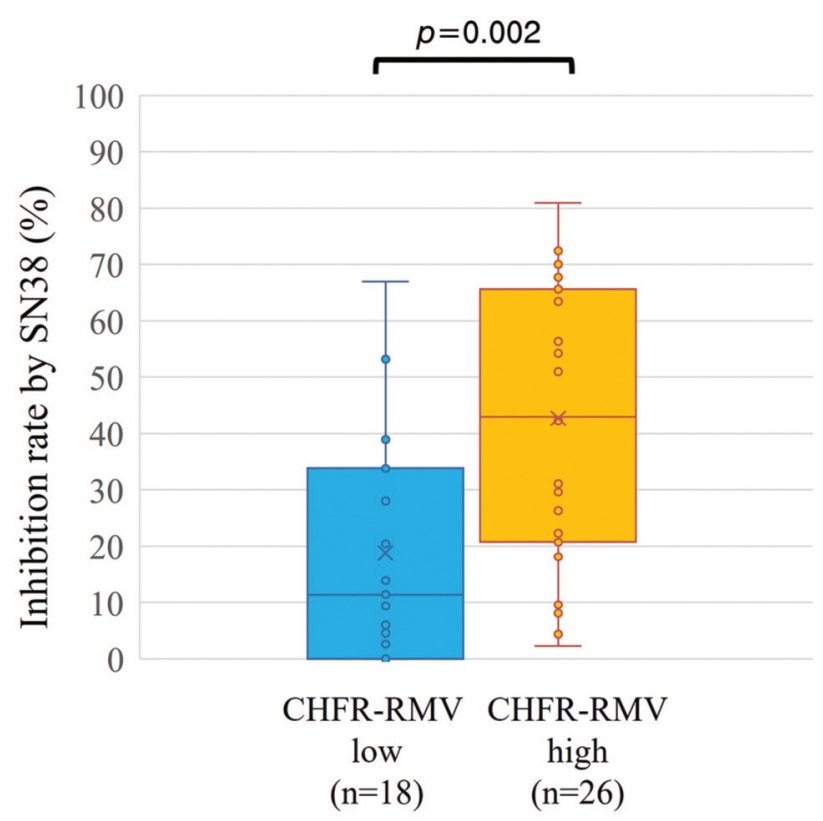

Figure 2. Comparison of efficacy of SN38 in the HDRA between CHFR$R M V$ high-and low-groups. The cohort tested with the HDRA was divided into two groups: CHFR-RMV high-and low-, based on a cutoff of 0.0001. The median inhibition rates of SN38 were $47.0 \%(2.3 \%$ $80.9 \%)$ in the CHFR-RMV high-group $(n=26)$ and $10.4 \%$ (0.0\%-66.9\%) in the CHFR-RMV low-group $(n=18)$. There was significantly greater inhibition by SN38 on patient tumors in the HDRA in the CHFR-RMV high-group ( $p=0.002)$. CHFR: Checkpoint-with-forkhead-and-ringfinger domains; HDRA: histoculture drug response assay; RMV: relative methylation value.

\section{Results}

Correlation of the efficacy of the irinotecan active- metabolite SN38 in the HDRA with CHFR-promoter methylation of CRC clinical specimens. CHFR-RMV was significantly positively correlated with inhibition by SN38 in the HDRA (Rs=0.37, $p=0.01$ ) (Figure 1). In contrast, CHFR-RMV was not correlated with inhibition by 5 -FU in the HDRA (Rs $=0.21$, $p=0.17$ ). The median inhibition rate by $\mathrm{SN} 38$ was $30.4 \%$ $(0.0 \%-80.9 \%)$. The chemosensitivity of tumors in the HDRA was defined as positive at an inhibition rate $\geq 50 \%(24,25)$, and the optimal cut-off for CHFR-RMV corresponding to an inhibition rate $\geq 50 \%$ was determined. A cut-off value of CHFR-RMV of 0.0001 gave the largest area under the curve (AUC) (AUC $=0.703, p=0.01$ ). The training cohort tested in the HDRA was then divided into two groups: CHFR-RMV high- and low-groups, based on the cut-off of 0.0001 . The median inhibition rates for SN38 were $47.0 \%(2.3 \%-80.9 \%)$ in the CHFR-RMV high-group $(\mathrm{n}=26)$ and $10.4 \%(0.0 \%$ $66.9 \%)$ in the CHFR-RMV low-group $(\mathrm{n}=18)$. There was a significantly higher inhibition by SN38 on tumors from patients in the CHFR-RMV high-group compared to the

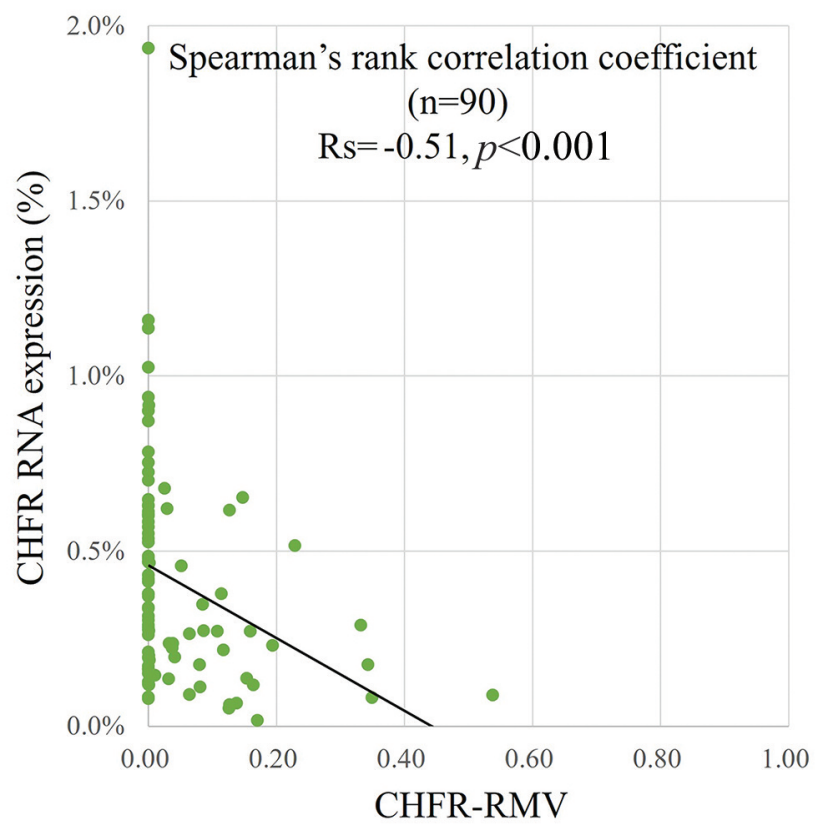

Figure 3. Correlation of CHFR-RMV and CHFR RNA expression in the entire cohort. There was a significantly negative correlation between CHFR-RMV and CHFR RNA expression in the entire cohort ( $n=90)$ $(R s=-0.51, p<0.001)$.

CHFR-RMV low-group in the HDRA ( $p=0.002)$ (Figure 2). Upon comparison of clinico-pathological factors between the two groups (Table I), univariate analysis indicated that the location of the primary tumor differed significantly ( $p=0.0001$ ), with patients in the CHFR-RMV high-group more likely to have right-sided CRC. There were no significant differences in other clinico-pathological factors between the groups (Table I).

Clinico-pathological characteristics in the low- and highCHFR-RMV patient training and test cohorts. The demographics of the patients in the test and training cohorts are shown in Table I. To examine the correlation of the CHFR-promoter methylation and the response to irinotecan-based systemic chemotherapy, the test cohort was divided into two groups: CHFR-RMV high$(n=28)$ and low- $(n=21)$. In univariate analysis, there were no significant differences between the groups.

Comparison of chemotherapy regimens in the low-and highCHFR-RMV patient cohorts. The details of the irinotecanbased systemic chemotherapy regimens are shown in Table II. These regimens included FOLFIRI ( $\mathrm{n}=13$ patients), IRIS $(\mathrm{n}=6)$, SIR $(\mathrm{n}=1)$, and irinotecan as a single agent $(\mathrm{n}=1)$ in the CHFR-RMV low-group; and FOLFIRI $(n=21)$, XELIRI $(n=1)$, IRIS $(n=5)$, and irinotecan as a single agent $(n=1)$ in the CHFR-RMV high-group. Anti-VEGF antibody was 
Table I. Patient characteristics.

\begin{tabular}{|c|c|c|c|c|c|c|c|}
\hline \multirow[b]{2}{*}{$\begin{array}{l}\text { Clinico-pathological } \\
\text { factors }\end{array}$} & \multirow[b]{2}{*}{ Variables } & \multicolumn{3}{|c|}{ Training cohort $(n=44)$} & \multicolumn{3}{|c|}{ Test cohort $(n=49)$} \\
\hline & & $\begin{array}{c}\text { CHFR-RMV } \\
\text { Low } \\
(n=18)\end{array}$ & $\begin{array}{c}\text { CHFR-RMV } \\
\text { High } \\
(\mathrm{n}=26)\end{array}$ & $p$-Value & $\begin{array}{c}\text { CHFR-RMV } \\
\text { Low } \\
(n=21)\end{array}$ & $\begin{array}{c}\text { CHFR-RMV } \\
\text { High } \\
(\mathrm{n}=28)\end{array}$ & $p$-Value \\
\hline Number of patients & & 18 & 26 & - & 21 & 28 & - \\
\hline Age & Years $^{\mathrm{a}}$ & $\begin{array}{c}69.5 \\
(45-88)\end{array}$ & $\begin{array}{c}70 \\
(43-84)\end{array}$ & 0.77 & $\begin{array}{c}61 \\
(25-80)\end{array}$ & $\begin{array}{c}65 \\
(40-83)\end{array}$ & 0.24 \\
\hline Gender & $\begin{array}{l}\text { Male } \\
\text { Female }\end{array}$ & $\begin{array}{l}9(50.0 \%) \\
9(50.0 \%)\end{array}$ & $\begin{array}{l}10(38.5 \%) \\
16(61.5 \%)\end{array}$ & 0.54 & $\begin{array}{l}12(57.1 \%) \\
9(42.9 \%)\end{array}$ & $\begin{array}{l}16(57.1 \%) \\
12(42.9 \%)\end{array}$ & 1.00 \\
\hline Location & $\begin{array}{l}\text { Colon } \\
\text { Rectum }\end{array}$ & $\begin{array}{l}16(88.9 \%) \\
2(11.1 \%)\end{array}$ & $\begin{aligned} & 25(96.2 \%) \\
& 1(3.9 \%)\end{aligned}$ & 0.56 & $\begin{array}{l}14(66.7 \%) \\
7(33.3 \%)\end{array}$ & $\begin{array}{l}21(75.0 \%) \\
7(25.0 \%)\end{array}$ & 0.54 \\
\hline Location & $\begin{array}{l}\text { Right-sided } \\
\text { Left-sided }\end{array}$ & $\begin{array}{c}1(5.6 \%) \\
17(94.4 \%)\end{array}$ & $\begin{array}{l}17(65.4 \%) \\
9(34.6 \%)\end{array}$ & 0.0001 & $\begin{array}{l}5(23.8 \%) \\
16(76.2 \%)\end{array}$ & $\begin{array}{l}8(28.6 \%) \\
20(71.4 \%)\end{array}$ & 0.76 \\
\hline $\begin{array}{l}\text { Serum CEA level at time of resection } \\
\text { of primary tumor }\end{array}$ & $\mathrm{ng} / \mathrm{ml}^{\mathrm{a}}$ & $\begin{array}{c}4.4 \\
(0.8-59.7)\end{array}$ & $\begin{array}{c}5.0 \\
(0.6-368)\end{array}$ & 0.73 & $\begin{array}{c}12.7 \\
(1.5-6,796)\end{array}$ & $\begin{array}{c}7.2 \\
(0.3-1,403)\end{array}$ & 0.25 \\
\hline $\begin{array}{l}\text { Maximum diameter } \\
\text { of primary tumor }\end{array}$ & $\mathrm{mm}^{\mathrm{a}}$ & $\begin{array}{c}45 \\
(30-70)\end{array}$ & $\begin{array}{c}50 \\
(23-180)\end{array}$ & 0.39 & $\begin{array}{c}50 \\
(30-200)\end{array}$ & $\begin{array}{c}49 \\
(27-90)\end{array}$ & 0.70 \\
\hline $\begin{array}{l}\text { Predominant histological } \\
\text { type of primary tumor }\end{array}$ & $\begin{array}{l}\text { Differentiated } \\
\text { Undifferentiated }\end{array}$ & $\begin{aligned} 17(94.4 \%) \\
1(5.6 \%)\end{aligned}$ & $\begin{array}{l}20(76.9 \%) \\
6(23.1 \%)\end{array}$ & 0.21 & $\begin{array}{l}17(81.0 \%) \\
4(19.1 \%)\end{array}$ & $\begin{array}{l}25(89.3 \%) \\
3(10.7 \%)\end{array}$ & 0.44 \\
\hline $\begin{array}{l}\text { Undifferentiated component } \\
\text { in primary tumor }\end{array}$ & $\begin{array}{l}\text { Present } \\
\text { Absent }\end{array}$ & $\begin{array}{l}4(22.2 \%) \\
14(77.8 \%)\end{array}$ & $\begin{array}{l}11(42.3 \%) \\
15(57.7 \%)\end{array}$ & 0.21 & $\begin{array}{c}6(28.6 \%) \\
15(71.4 \%)\end{array}$ & $\begin{array}{l}9(32.1 \%) \\
19(67.9 \%)\end{array}$ & 1.00 \\
\hline T-classification & $\begin{array}{l}\mathrm{T} 1-3 \\
\mathrm{~T} 4\end{array}$ & $\begin{array}{c}17(94.4 \%) \\
1(5.6 \%)\end{array}$ & $\begin{array}{c}23(88.5 \%) \\
3(11.5 \%)\end{array}$ & 0.63 & $\begin{array}{l}13(61.9 \%) \\
8(38.1 \%)\end{array}$ & $\begin{array}{c}22(78.6 \%) \\
6(21.4 \%)\end{array}$ & 0.22 \\
\hline $\mathrm{N}$-classification & $\begin{array}{c}\text { N0 } \\
\text { N1, } 2\end{array}$ & $\begin{array}{l}10(55.6 \%) \\
8(44.4 \%)\end{array}$ & $\begin{array}{l}16(61.5 \%) \\
10(38.5 \%)\end{array}$ & 0.76 & $\begin{array}{l}5(23.8 \%) \\
16(76.2 \%)\end{array}$ & $\begin{array}{c}3(10.7 \%) \\
25(89.3 \%)\end{array}$ & 0.26 \\
\hline Metastatic site ${ }^{b}$ & $\begin{array}{c}\text { Liver } \\
\text { Lung } \\
\text { Peritoneum } \\
\text { Local } \\
\text { Para-aortic LN } \\
\text { Others }\end{array}$ & $\begin{array}{c}3(16.7 \%) \\
0(0 \%) \\
0(0 \%) \\
0(0 \%) \\
0(0 \%) \\
0(0 \%)\end{array}$ & $\begin{array}{c}3(11.5 \%) \\
1(3.8 \%) \\
1(3.8 \%) \\
0(0 \%) \\
0(0 \%) \\
0(0 \%)\end{array}$ & - & $\begin{array}{c}10(47.6 \%) \\
11(52.4 \%) \\
2(9.5 \%) \\
1(4.8 \%) \\
2(9.5 \%) \\
3(14.3 \%)\end{array}$ & $\begin{array}{c}18(64.3 \%) \\
12(42.9 \%) \\
2(7.1 \%) \\
1(3.6 \%) \\
1(3.6 \%) \\
5(17.9 \%)\end{array}$ & - \\
\hline $\begin{array}{l}\text { Stage at resection } \\
\text { of primary tumor }\end{array}$ & $\begin{array}{l}\text { I-III } \\
\text { IV }\end{array}$ & $\begin{array}{c}15(83.3 \%) \\
3(16.7 \%)\end{array}$ & $\begin{array}{l}22(84.6 \%) \\
4(15.4 \%)\end{array}$ & 1.00 & $\begin{array}{l}8(38.1 \%) \\
13(61.9 \%)\end{array}$ & $\begin{array}{l}10(35.7 \%) \\
18(64.3 \%)\end{array}$ & 1.00 \\
\hline & Wild & $1(5.6 \%)$ & $4(15.4 \%)$ & 0.42 & $10(47.6 \%)$ & $16(57.1 \%)$ & 0.57 \\
\hline RAS & $\begin{array}{l}\text { Mutant } \\
\text { Unknown } \\
\text { Wild }\end{array}$ & $\begin{array}{c}2(11.1 \%) \\
15(83.3 \%) \\
0(0 \%)\end{array}$ & $\begin{array}{c}1(3.8 \%) \\
21(80.8 \%) \\
3(11.5 \%)\end{array}$ & 0.26 & $\begin{array}{c}10(47.6 \%) \\
1(4.8 \%) \\
2(13.3 \%)\end{array}$ & $\begin{array}{c}11(39.3 \%) \\
1(3.6 \%) \\
5(17.9 \%)\end{array}$ & 0.71 \\
\hline UGT1A1 gene ${ }^{c}$ & $\begin{array}{l}\text { Variant } \\
\text { Unknown }\end{array}$ & $\begin{array}{c}0(0 \%) \\
18(100 \%)\end{array}$ & $\begin{array}{c}0(0 \%) \\
23(88.5 \%)\end{array}$ & & $\begin{array}{l}6(30.0 \%) \\
13(56.7 \%)\end{array}$ & $\begin{array}{c}7(25.0 \%) \\
16(57.1 \%)\end{array}$ & \\
\hline
\end{tabular}

aMedian (minimum-maximum); bduplication involved. cUGT1A1 protein degrades SN38.

added in 16 patients in the CHFR-RMV low-group and 20 patients in the CHFR-RMV high-group. Anti-EGFR antibody was added in 3 patients and 6 patients, respectively, in the two groups. Use of irinotecan-based systemic chemotherapy regimens did not differ significantly between the two groups. These regimens were administered as first-line therapy in 13 patients in the CHFR-RMV low-group and in 12 patients in the CHFR-RMV high-group. There was also no significant difference in the use of the regimens as first-line systemic chemotherapy between the two groups (Table II).

Correlation of CHFR-RMV and CHFR RNA expression in the entire cohort. There was a significantly negative correlation between CHFR-RMV and CHFR RNA expression in the entire cohort $(\mathrm{n}=90)(\mathrm{Rs}=-0.51, p<0.001)$ (Figure 3).

Correlation of CHFR-RMV status and response to irinotecanbased systemic chemotherapy in the test cohort. First, we compared the best overall responses to irinotecan-based systemic chemotherapy between the CHFR-RMV high- and low-groups (Figure 4). The CHFR-RMV low-group included cases with a partial response (PR) $(n=3,14.3 \%)$, stable disease $(\mathrm{SD})(\mathrm{n}=6,28.6 \%)$ and progressive disease (PD) $(\mathrm{n}=12,57.1 \%)$. The CHFR-RMV high-group included cases with PR $(n=8,28.6 \%)$, SD $(n=13,46.4 \%)$ and PD $(n=7$, $25.0 \%$ ). There was a trend towards better overall responses 
Table II. Details of irinotecan-based systemic chemotherapy regimens.

\begin{tabular}{|c|c|c|c|c|c|c|c|c|}
\hline \multirow{4}{*}{$\begin{array}{l}\text { Regimen } \\
\text { Regimen }\end{array}$} & \multicolumn{4}{|c|}{ All patients in the test cohort } & \multirow{2}{*}{\multicolumn{4}{|c|}{$\begin{array}{c}\text { Patients treated with first-line systemic } \\
\text { chemotherapy with irinotecan } \\
\text { CHFR-RMV }\end{array}$}} \\
\hline & \multicolumn{4}{|c|}{ CHFR-RMV } & & & & \\
\hline & \multicolumn{2}{|c|}{$\begin{array}{c}\text { Low group } \\
\mathrm{n}=21(\%)\end{array}$} & \multicolumn{2}{|c|}{$\begin{array}{c}\text { High group } \\
\mathrm{n}=28(\%)\end{array}$} & \multicolumn{2}{|c|}{$\begin{array}{c}\text { Low group } \\
\mathrm{n}=13(\%)\end{array}$} & \multicolumn{2}{|c|}{$\begin{array}{l}\text { High group } \\
\mathrm{n}=12(\%)\end{array}$} \\
\hline & & & & & & & & \\
\hline FOLFIRI & 0 & $(0.0 \%)$ & 1 & $(3.6 \%)$ & 0 & $(0.0 \%)$ & 0 & $(0.0 \%)$ \\
\hline FOLFIRI+bevacizumab & 10 & $(47.6 \%)$ & 14 & $(50.0 \%)$ & 5 & $(38.5 \%)$ & 6 & $(50.0 \%)$ \\
\hline FOLFIRI+ramucirumab & 0 & $(0.0 \%)$ & 1 & $(3.6 \%)$ & 0 & $(0.0 \%)$ & 0 & $(0.0 \%)$ \\
\hline FOLFIRI+cetuximab & 1 & $(4.8 \%)$ & 2 & $(7.1 \%)$ & 1 & $(7.7 \%)$ & 1 & $(8.3 \%)$ \\
\hline FOLFIRI+panitumumab & 2 & $(9.5 \%)$ & 3 & $(10.7 \%)$ & 2 & $(15.4 \%)$ & 2 & $(16.7 \%)$ \\
\hline XELIRI+bevacizumab & 0 & $(0.0 \%)$ & 1 & $(3.6 \%)$ & 0 & $(0.0 \%)$ & 0 & $(0.0 \%)$ \\
\hline IRIS & 1 & $(4.8 \%)$ & 1 & $(3.6 \%)$ & 1 & $(7.7 \%)$ & 0 & $(0.0 \%)$ \\
\hline IRIS+bevacizumab & 5 & $(23.8 \%)$ & 4 & $(14.3 \%)$ & 3 & $(23.1 \%)$ & 2 & $(16.7 \%)$ \\
\hline SIR+bevacizumab & 1 & $(4.8 \%)$ & 0 & $(0.0 \%)$ & 0 & $(0.0 \%)$ & 0 & $(0.0 \%)$ \\
\hline Irinotecan alone & 1 & $(4.8 \%)$ & 0 & $(0.0 \%)$ & 1 & $(7.7 \%)$ & 0 & $(0.0 \%)$ \\
\hline Irinotecan+panitumumab & 0 & $(0.0 \%)$ & 1 & $(3.6 \%)$ & 0 & $(0.0 \%)$ & 1 & $(8.3 \%)$ \\
\hline Total & 21 & $(100 \%)$ & 28 & $(100 \%)$ & 13 & $(100 \%)$ & 12 & $(100 \%)$ \\
\hline \multicolumn{9}{|l|}{ Molecular-targeted agents } \\
\hline Anti-VEGF antibodya & 16 & $(76.2 \%)$ & 20 & $(71.4 \%)$ & 8 & $(61.5 \%)$ & 8 & $(66.7 \%)$ \\
\hline Anti-EGFR antibody ${ }^{b}$ & 3 & $(14.3 \%)$ & 6 & $(21.4 \%)$ & 3 & $(23.1 \%)$ & 4 & $(33.3 \%)$ \\
\hline None & 2 & $(9.5 \%)$ & 2 & $(7.1 \%)$ & 2 & $(15.4 \%)$ & 0 & $(0.0 \%)$ \\
\hline Total & 21 & $(100 \%)$ & 28 & $(100 \%)$ & 13 & $(100 \%)$ & 12 & $(100 \%)$ \\
\hline
\end{tabular}

aVEGF: Vascular endothelial growth factor; bEGFR: epidermal growth factor receptor.

in the CHFR-RMV high-group ( $p=0.07)$. The CHFR-RMV high-group had a significantly better disease control (PR+SD) rate $(75.0 \%$ vs. $42.9 \%, p=0.04)$ (Figure 4). A similar comparison of best overall-responses in patients who received first-line systemic chemotherapy with irinotecan also showed a trend for a better disease-control rate in the CHFR-RMV high-group ( $83.3 \%$ vs. $46.2 \%, p=0.10)$ (Figure 5 ). In patients who also received FOLFIRI+bevacizumab as first-line systemic chemotherapy, which was the most frequent regimen in the cohort, the disease control rate was also higher in the CHFR-RMV high-group ( $83.3 \%$ vs. $40.0 \%)$, although the difference was not significant due to the small number of patients $(p=0.24)$.

We also analyzed long-term outcomes in the test cohort through comparison of cancer-specific (CSS) and progressionfree (PFS) survival in the CHFR-RMV high- and low- groups (Figure 6). There was no significant difference in CSS from the time of initial diagnosis of advanced or metastatic CRC between the two groups [CHFR-RMV high-group: HR=1.12 $(0.55-2.26) ; p=0.76]$ (Figure 6A). Similarly, there was no significant difference in CSS from the time of resection of the primary tumor [CHFR-RMV high-group: HR=1.30 (0.632.66); $p=0.48$ ] (Figure 6B). Regarding PFS from the time of initiation of systemic chemotherapy with irinotecan, the CHFR-RMV high-group showed a trend towards a better PFS in the test cohort [HR=0.54 (0.28-1.04); $p=0.07]$ (Figure 6C). This trend was maintained in patients treated with first-line systemic chemotherapy with irinotecan in the CHFR-RMV high-group [HR=0.39 (0.13-1.12); $p=0.08$ ] (Figure 6D). In patients treated with FOLFIRI+bevacizumab as first-line systemic chemotherapy, the most frequently-used regimen, the CHFR-RMV high-group had significantly better PFS ( $p=0.01$ by log-rank test; the Cox proportional hazard regression model did not converge) (Figure 6E).

\section{Discussion}

Cha et al. (9) found that CHFR promoter-methylation was associated with prolonged TTP and OS in patients treated with irinotecan-based systemic chemotherapy for advanced or metastatic CRC, and also showed increased sensitivity to irinotecan in CHFR-methylated cell lines. These in vivo and in vitro results are consistent with our findings, despite the use of qualitative MSP by Cha et al. (9), rather than quantitative MSP as in the present report.

CHFR encodes a checkpoint protein that delays entry into metaphase (26). This suggests that cancer cells that are deficient in CHFR may be more susceptible to microtubule inhibitors such as taxanes. Cha et al. (9) suggested that the association of CHFR-promoter methylation with the response 


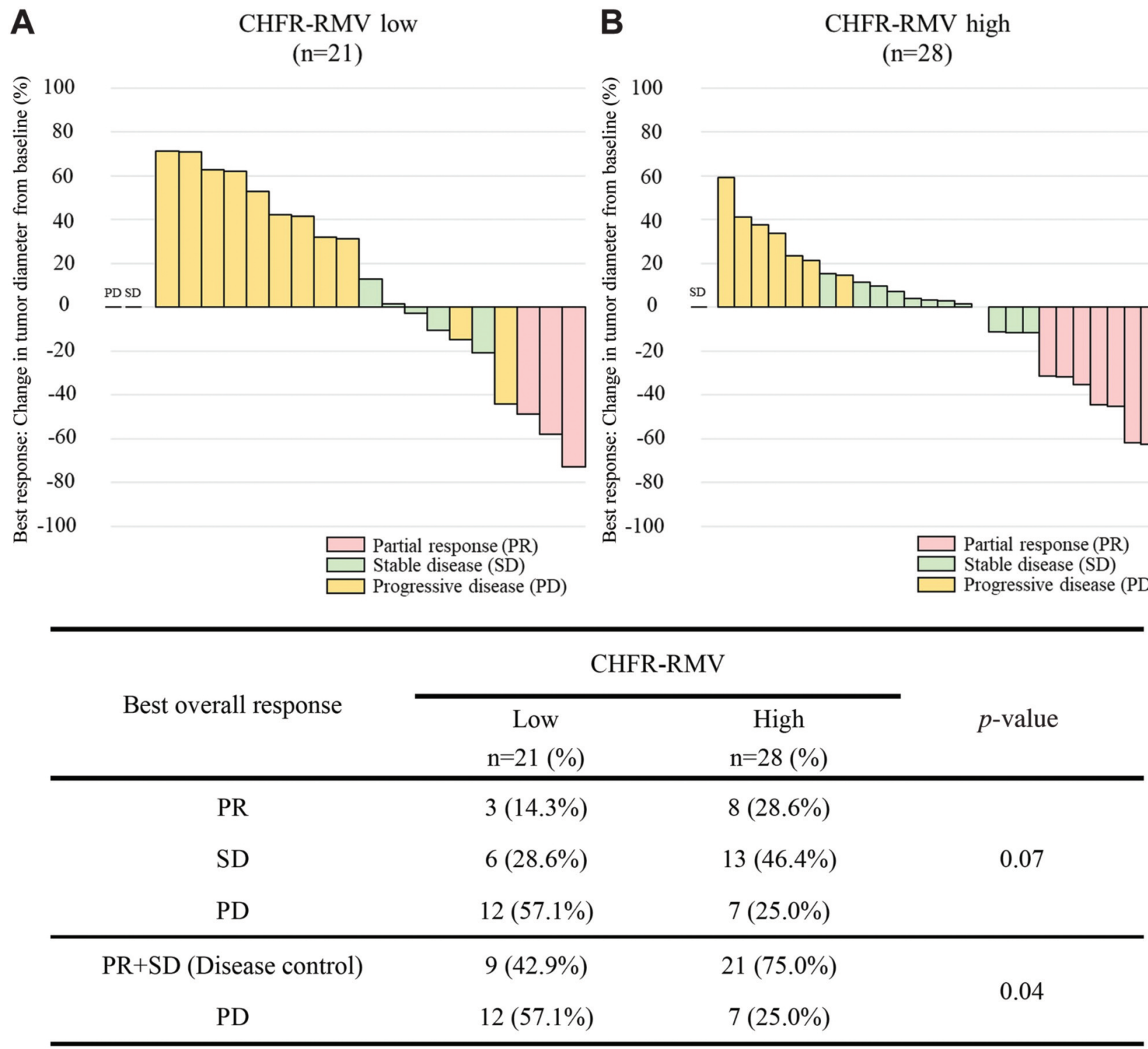

Figure 4. Best overall responses between the CHFR-RMV high- and low-groups. (A) CHFR-RMV low; (B) CHFR-RMV high. The CHFR-RMV lowgroup included cases with a $P R(n=3,14.3 \%), S D(n=6,28.6 \%)$ and $P D(n=12,57.1 \%)$; whereas the CHFR-RMV high-group had $P R(n=8,28.6 \%)$, $S D(n=13,46.4 \%)$ and $P D(n=7,25.0 \%)$. There was a trend towards better overall responses in the CHFR-RMV high-group ( $p=0.07)$, with this group having a significantly better disease-control $(P R+S D)$ rate $(75.0 \%$ vs. $42.9 \%, p=0.04)$. CHFR: Checkpoint-with-forkhead-and-ring-finger domains; RMV: relative methylation value; PD: progressive disease; PR: partial response; SD: stable disease.

to irinotecan may be based mechanistically on the role of CHFR in protein ubiquitination, as an E3 ubiquitin ligase (27). Irinotecan is a topoisomerase I inhibitor that can induce DNA damage (28). Therefore, repair of irinotecan-induced DNA damage is likely to be a mechanism of irinotecan resistance (29). A decrease in the level of CHFR protein due to DNA methylation will impair ubiquitination of topoisomerase I, and the subsequent upregulation of topoisomerase I may render cancer cells more sensitive to irinotecan-induced damage (9).
To examine this hypothesis, we used SN38 in the HDRA, rather than the more common use of irinotecan $(30,31)$, since SN38 is the active metabolite of irinotecan and a potent inhibitor of DNA topoisomerase I (32). Irinotecan is converted to SN38 by carboxylesterase enzymes (33). Therefore, the present HDRA study is the first to evaluate the correlation between the efficacy of SN38 and CHFRpromoter methylation directly. The present HDRA study showed no association between response to 5-FU and CHFR- 

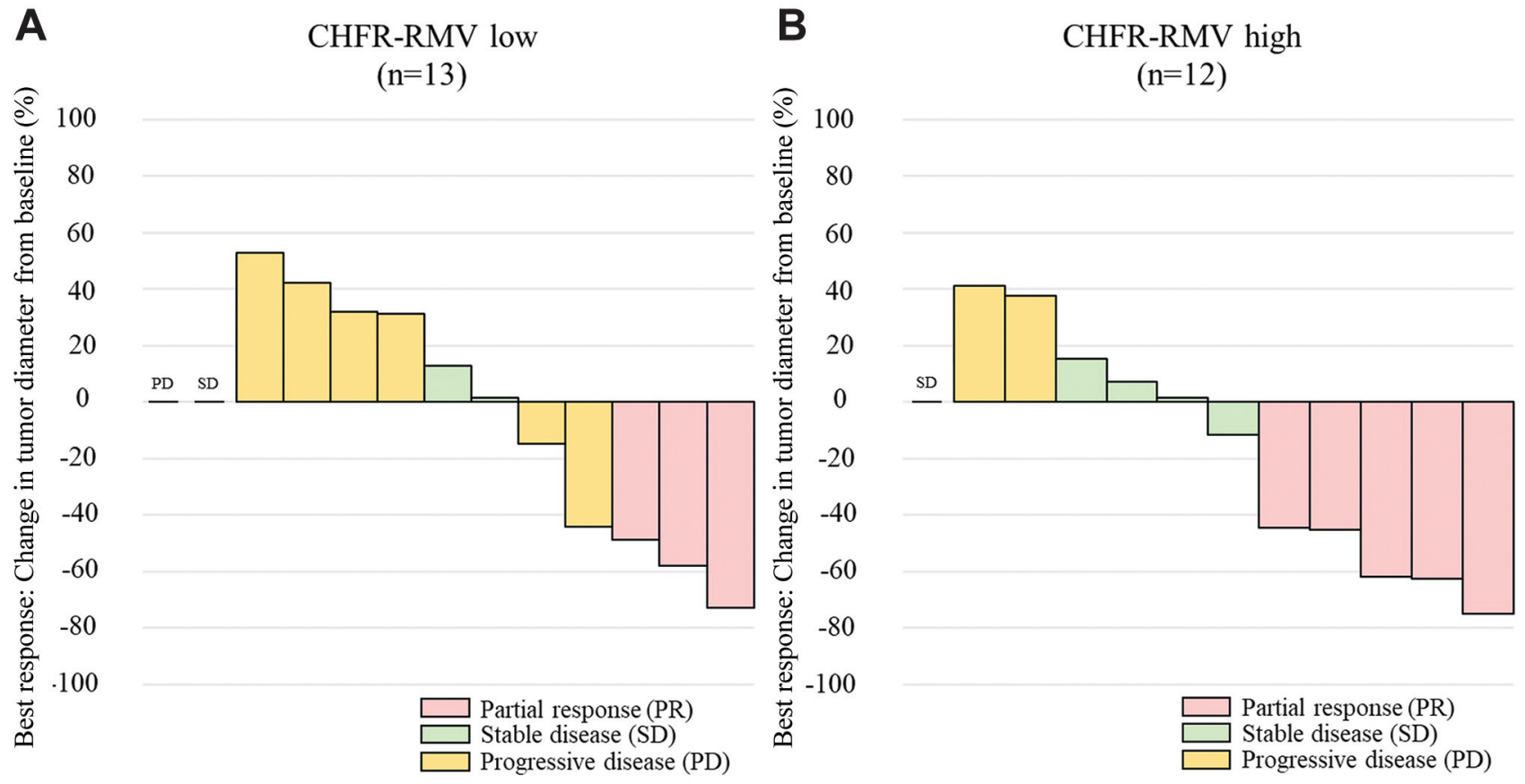

\begin{tabular}{cccc}
\hline & \multicolumn{2}{c}{ CHFR-RMV } & \\
\cline { 2 - 3 } Best overall response & $\begin{array}{c}\text { Low } \\
\mathrm{n}=13(\%)\end{array}$ & $\begin{array}{c}\text { High } \\
\mathrm{n}=12(\%)\end{array}$ & \\
\cline { 2 - 3 } & $3(23.1 \%)$ & $5(41.7 \%)$ & \\
\hline PR & $3(23.1 \%)$ & $5(41.7 \%)$ & 0.15 \\
SD & $7(53.8 \%)$ & $2(16.7 \%)$ & \\
PD & $6(46.2 \%)$ & $10(83.3 \%)$ & 0.10 \\
\hline PR+SD (Disease control) & $7(53.8 \%)$ & $2(16.7 \%)$ & \\
\hline PD & &
\end{tabular}

Figure 5. Best overall responses in patients who received first-line systemic chemotherapy with irinotecan between CHFR-RMV high-and lowgroups. (A) CHFR-RMV low; (B) CHFR-RMV high. A comparison of overall responses in patients who received first-line systemic chemotherapy with irinotecan showed a trend for a better disease-control rate in the CHFR-RMV high-group (83.3\% vs. 46.2\%, p=0.10). CHFR: Checkpointwith-forkhead-and-ring-finger domains; RMV: relative-methylation value.

promoter methylation in vitro, suggesting a specific positive correlation of CHFR promoter-methylation and response to SN38. Only one previous report has determined the inhibitory effect of irinotecan itself in colorectal cancer tissues in the HDRA, with the finding of a median inhibition rate of $11.4 \%$ in 22 CRC patients (34). The higher inhibition rate found in the present study may be because SN38 is much more potent than irinotecan itself (35).

We also found a significant positive correlation between the clinical response of irinotecan-based systemic chemotherapy and CHFR-promoter methylation in patients. Especially, it is important that there were clinical benefits in patients in longterm outcomes (i.e., PFS). Thus, evaluation of CHFRpromoter methylation can identify patients who may benefit from irinotecan-based systemic chemotherapy.

There are several limitations in this study. First, only a small number of patients were enrolled due to enrollment being limited to a single center. Second, the regimens of irinotecan-based systemic chemotherapy were not consistent because of the retrospective study design. In particular, the 

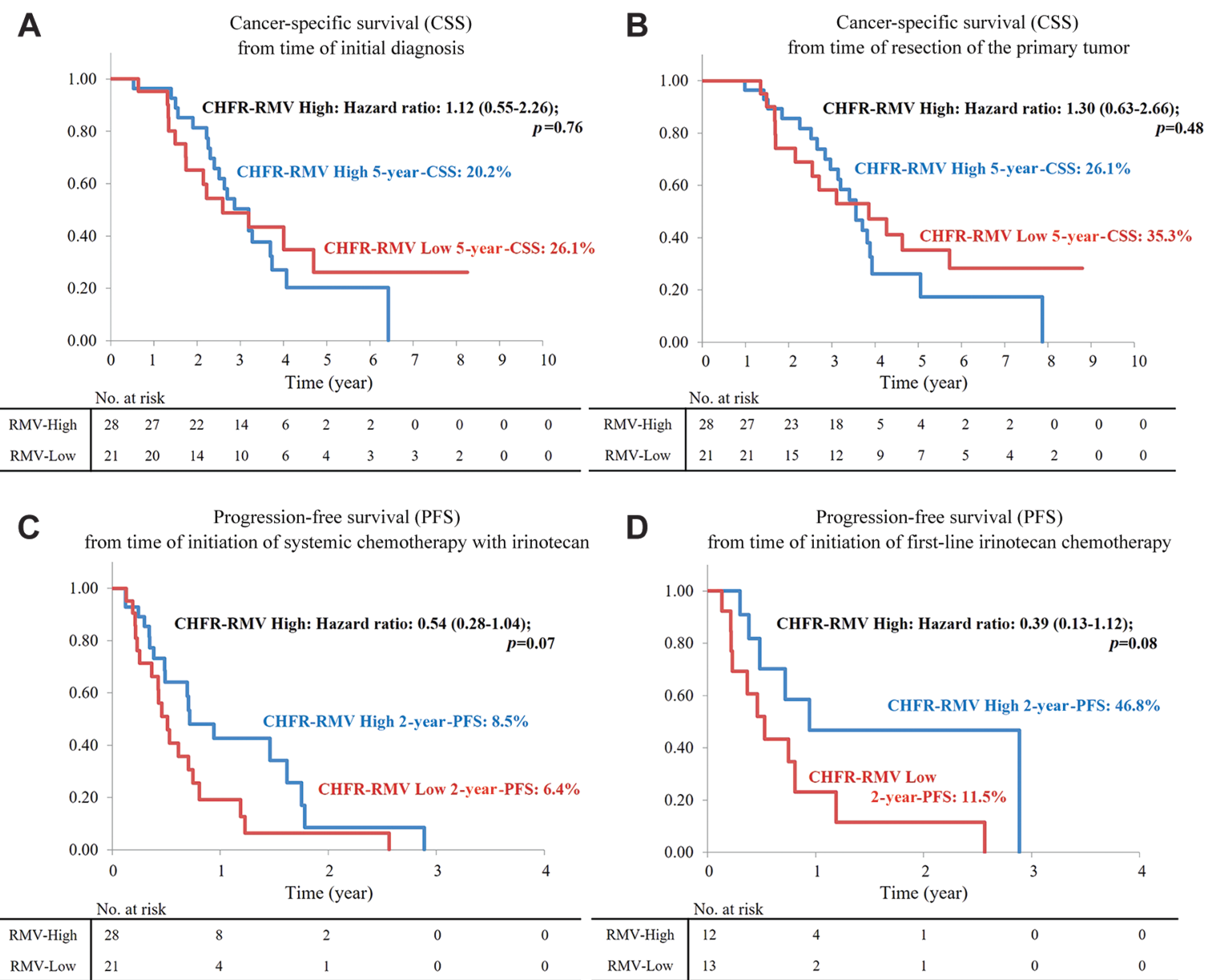

D Progression-free survival (PFS)

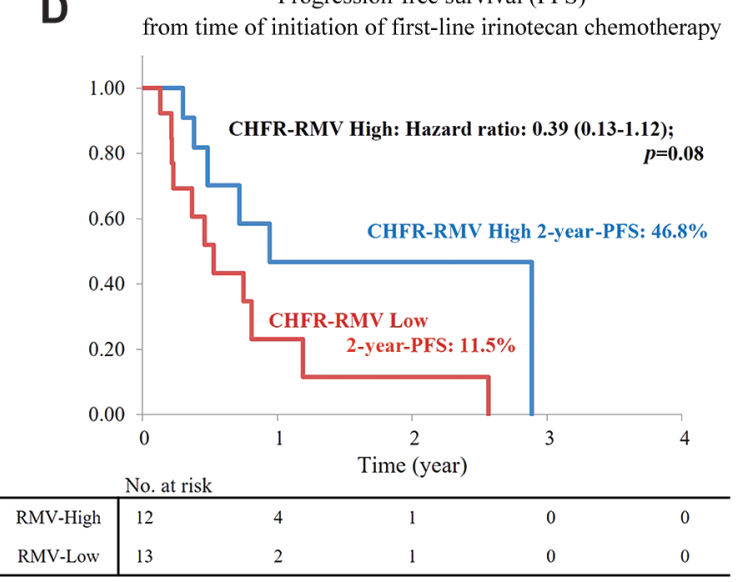

E

Progression-free survival (PFS)

from time of initiation of FOLFIRI+bevacizumab as first-line chemotherapy

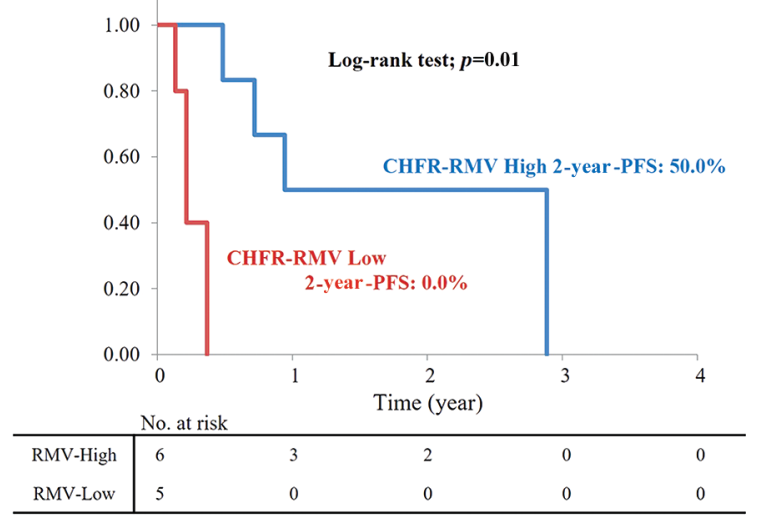

Figure 6. Long-term outcomes of CRC patients treated with irinotecan-based chemotherapy in the test cohort. Long-term outcome was analyzed in the test cohort by comparison of cancer-specific (CSS) and progression-free (PFS) survival in the CHFR-RMV high-and low-groups. (A) There was no difference in CSS from the time of initial diagnosis of advanced or metastatic CRC between the two groups [CHFR-RMV high-group: HR=1.12 (0.55-2.26); $p=0.76]$. (B) Similarly, there was no significant difference in CSS from the time of resection of the primary tumor [CHFR-RMV high-group: HR=1.30 (0.63-2.66); $p=0.48]$. (C) For PFS from the time of initiation of systemic chemotherapy with irinotecan, the CHFR-RMV high-group showed a trend towards better PFS in the test cohort [HR=0.54 (0.28-1.04); $p=0.07]$. (D) This trend was maintained in patients treated with first-line systemic chemotherapy with irinotecan in the CHFR-RMV high-group [HR=0.39 (0.13-1.12); $p=0.08]$. (E) In patients treated with FOLFIRI+bevacizumab as first-line systemic chemotherapy, the CHFR-RMV high-group had significantly better PFS ( $p=0.01$ by log-rank test; the Cox proportional hazard regression model did not converge). CHFR: Checkpoint-with-forkhead-and-ring-finger domains; RMV: relative-methylation value; CRC: colorectal cancer; HR: hazard ratio. 
influence of molecular-targeted agents on drug response cannot be ignored. However, a previous study gave similar results in a study cohort in which most patients (>90\%) were not treated with molecular-targeted agents in combination with irinotecan-based systemic chemotherapy (9). Therefore, it is likely that the mechanisms demonstrated by the present results apply to the effects of irinotecan (SN38) alone.

Since there is no toxicity limit on the cumulative dose of irinotecan, unlike oxaliplatinum, it is preferable for patients with advanced or metastatic CRC to continue to receive irinotecan-based systemic chemotherapy. The present results show a positive correlation between increased sensitivity to irinotecan (SN38) and CHFR promoter methylation both in vitro and in vivo. Our results support the importance of evaluation of CHFR-promoter methylation for patients with advanced or metastatic CRC. Our results also demonstrate the benefits of using the HDRA for patients. A prospective study is warranted to expand our findings.

\section{Conflicts of Interest}

The Authors declare that they have no conflicts of interest in relation to this study.

\section{Authors' Contributions}

$\mathrm{TH}$ and Sugimoto K developed the concept of the study and drafted the article. TH and Sugimoto $\mathrm{K}$ performed histoculture drug response assay (HDRA) with the assistance of SRL, Inc (Tokyo, Japan). TH, Sugimoto K, HM and TI performed genomic DNA extraction, bisulfite treatment, quantitative methylation-specific PCR (qMSP), RNA extraction and real-time quantitative PCR (RTPCR). TH, Sugimoto K and TI performed the patient survey and analyzed data. KH, YO, MK, SK, MT, YK, NS, AN and Sakamoto $\mathrm{K}$ recruited patients. TH, Sugimoto $\mathrm{K}$ and Sakamoto K obtained IRB approval for the protocol of the study. The article was revised by RMH. The article has been approved by all Authors.

\section{Acknowledgements}

This work was supported by the Grant-in-aid for Scientific Research, Japanese Society for the Promotion of Science (17K16580).

\section{References}

1 Sung H, Ferlay J, Siegel RL, Laversanne M, Soerjomataram I, Jemal A and Bray F: Global cancer statistics 2020: GLOBOCAN estimates of incidence and mortality worldwide for 36 cancers in 185 countries. CA Cancer J Clin 71(3): 209-249, 2021. PMID: 33538338. DOI: $10.3322 /$ caac. 21660

2 Piso P, Arnold D and Glockzin G: Challenges in the multidisciplinary management of stage IV colon and rectal cancer. Expert Rev Gastroenterol Hepatol 9(3): 317-326, 2015. PMID: 25192718. DOI: 10.1586/17474124.2015.957273

3 van de Velde CJ, Boelens PG, Tanis PJ, Espin E, Mroczkowski P, Naredi P, Pahlman L, Ortiz H, Rutten HJ, Breugom AJ, Smith
JJ, Wibe A, Wiggers T and Valentini V: Experts reviews of the multidisciplinary consensus conference colon and rectal cancer 2012: science, opinions and experiences from the experts of surgery. Eur J Surg Oncol 40(4): 454-468, 2014. PMID: 24268926. DOI: $10.1016 /$ j.ejso.2013.10.013

4 Majer M, Akerley W and Kuwada SK: Oncologists' current opinion on the treatment of colon carcinoma. Anticancer Agents Med Chem 7(5): 492-503, 2007. PMID: 17896910. DOI: $10.2174 / 187152007781668742$

5 O'Neil BH and Goldberg RM: Innovations in chemotherapy for metastatic colorectal cancer: an update of recent clinical trials. Oncologist 13(10): 1074-1083, 2008. PMID: 18922828. DOI: 10.1634/theoncologist.2008-0083

6 Tournigand C, André T, Achille E, Lledo G, Flesh M, MeryMignard D, Quinaux E, Couteau C, Buyse M, Ganem G, Landi B, Colin P, Louvet $\mathrm{C}$ and de Gramont A: FOLFIRI followed by FOLFOX6 or the reverse sequence in advanced colorectal cancer: a randomized GERCOR study. J Clin Oncol 22(2): 229237, 2004. PMID: 14657227. DOI: 10.1200/JCO.2004.05.113

7 Aparicio J, Esposito F, Serrano S, Falco E, Escudero P, Ruiz-Casado A, Manzano H and Fernandez-Montes A: Metastatic colorectal cancer. First line therapy for unresectable disease. J Clin Med 9(12): 3889, 2020. PMID: 33265959. DOI: 10.3390/jcm9123889

8 Argyriou AA, Cavaletti G, Briani C, Velasco R, Bruna J, Campagnolo M, Alberti P, Bergamo F, Cortinovis D, Cazzaniga M, Santos C, Papadimitriou K and Kalofonos HP: Clinical pattern and associations of oxaliplatin acute neurotoxicity: a prospective study in 170 patients with colorectal cancer. Cancer 119(2): 438-444, 2013. PMID: 22786764. DOI: 10.1002/cncr.27732

9 Cha Y, Kim SY, Yeo HY, Baek JY, Choi MK, Jung KH, Dong SM and Chang HJ: Association of CHFR promoter methylation with treatment outcomes of irinotecan-based chemotherapy in metastatic colorectal cancer. Neoplasia 21(1): 146-155, 2019. PMID: 30562637. DOI: 10.1016/j.neo.2018.11.010

10 Diala ES and Hoffman RM: Hypomethylation of HeLa cell DNA and the absence of 5-methylcytosine in SV40 and adenovirus (type 2) DNA: analysis by HPLC. Biochem Biophys Res Commun 107(1): 19-26, 1982. PMID: 6289818. DOI: 10.1016/0006-291x(82)91663-1

11 Okugawa Y, Grady WM and Goel A: Epigenetic alterations in colorectal cancer: emerging biomarkers. Gastroenterology 149(5): 1204-1225.e12, 2015. PMID: 26216839. DOI: 10.1053/ j.gastro.2015.07.011

12 Lao VV and Grady WM: Epigenetics and colorectal cancer. Nat Rev Gastroenterol Hepatol 8(12): 686-700, 2011. PMID: 22009203. DOI: $10.1038 /$ nrgastro.2011.173

13 Lam K, Pan K, Linnekamp JF, Medema JP and Kandimalla R: DNA methylation based biomarkers in colorectal cancer: A systematic review. Biochim Biophys Acta 1866(1): 106-120, 2016. PMID: 27385266. DOI: 10.1016/j.bbcan.2016.07.001

14 Gao D, Herman JG and Guo M: The clinical value of aberrant epigenetic changes of DNA damage repair genes in human cancer. Oncotarget 7(24): 37331-37346, 2016. PMID: 26967246. DOI: $10.18632 /$ oncotarget.7949

15 Eisenhauer EA, Therasse P, Bogaerts J, Schwartz LH, Sargent D, Ford R, Dancey J, Arbuck S, Gwyther S, Mooney M, Rubinstein L, Shankar L, Dodd L, Kaplan R, Lacombe D and Verweij J: New response evaluation criteria in solid tumours: revised RECIST guideline (version 1.1). Eur J Cancer 45(2): 228-247, 2009. PMID: 19097774. DOI: 10.1016/j.ejca.2008.10.026 
16 Japanese Society for Cancer of the Colon and Rectum: Japanese classification of colorectal, appendiceal, and anal carcinoma: the 3d English edition [secondary publication]. J Anus Rectum Colon 3(4): 175-195, 2019. PMID: 31768468. DOI: 10.23922/ jarc.2019-018

17 Brierley JD, Gospodarowicz MK and Wittekind C: TNM Classification of Malignant Tumours, Eighth Edition. Hoboken John Wiley \& Sons, 2017.

18 Vescio RA, Redfern CH, Nelson TJ, Ugoretz S, Stern PH and Hoffman RM: In vivo-like drug responses of human tumors growing in three-dimensional gel-supported primary culture Proc Natl Acad Sci U.S.A. 84(14): 5029-5033, 1987. PMID: 3474637. DOI: 10.1073/pnas.84.14.5029

19 Kubota T, Sasano N, Abe O, Nakao I, Kawamura E, Saito T, Endo M, Kimura K, Demura H and Sasano H: Potential of the histoculture drug-response assay to contribute to cancer patient survival. Clin Cancer Res 1(12): 1537-1543, 1995. PMID: 9815954.

20 Furukawa T, Kubota T and Hoffman RM: Clinical applications of the histoculture drug response assay. Clin Cancer Res 1(3): 305-311, 1995. PMID: 9815986.

21 Furukawa T, Kubota T, Tanino H, Oura S, Yuasa S, Murate H, Morita K, Kozakai K, Yano $\mathrm{T}$ and Hoffman RM: Chemosensitivity of breast cancer lymph node metastasis compared to the primary tumor from individual patients tested in the histoculture drug response assay. Anticancer Res 20(5C): 3657-3658, 2000. PMID: 11268434.

22 Hulbert A, Jusue-Torres I, Stark A, Chen C, Rodgers K, Lee B, Griffin C, Yang A, Huang P, Wrangle J, Belinsky SA, Wang TH, Yang SC, Baylin SB, Brock MV and Herman JG: Early detection of lung cancer using DNA promoter hypermethylation in plasma and sputum. Clin Cancer Res 23(8): 1998-2005, 2017. PMID: 27729459. DOI: 10.1158/1078-0432.CCR-16-1371

23 Sugimoto K, Ito T, Hulbert A, Chen C, Orita H, Maeda M, Moro H, Fukagawa T, Ushijima T, Katai H, Wada R, Sato K, Sakamoto K, Yu W, Considine M, Cope L and Brock MV: DNA methylation genome-wide analysis in remnant and primary gastric cancers. Gastric Cancer 22(6): 1109-1120, 2019. PMID: 30863929. DOI: 10.1007/s10120-019-00949-5

24 Hoffman RM: Three-dimensional histoculture: origins and applications in cancer research. Cancer Cells 3(3): 86-92, 1991. PMID: 2054260.

25 Furukawa T, Kubota T, Watanabe M, Takahara T, Yamaguchi H, Takeuchi T, Kase S, Kodaira S, Ishibiki K and Kitajima M: High in vitro-in vivo correlation of drug response using sponge-gelsupported three-dimensional histoculture and the MTT end point Int J Cancer 51(3): 489-498, 1992. PMID: 1592540. DOI: $10.1002 / \mathrm{ijc} .2910510325$

26 Scolnick DM and Halazonetis TD: Chfr defines a mitotic stress checkpoint that delays entry into metaphase. Nature 406(6794): 430-435, 2000. PMID: 10935642. DOI: 10.1038/35019108
27 Derks S, Cleven AH, Melotte V, Smits KM, Brandes JC, Azad $\mathrm{N}$, van Criekinge $\mathrm{W}$, de Bruïne AP, Herman JG and van Engeland M: Emerging evidence for CHFR as a cancer biomarker: from tumor biology to precision medicine. Cancer Metastasis Rev 33(1): 161-171, 2014. PMID: 24375389. DOI: 10.1007/s10555-013-9462-4

28 Thomas A and Pommier Y: Targeting topoisomerase I in the era of precision medicine. Clin Cancer Res 25(22): 6581-6589, 2019. PMID: 31227499. DOI: 10.1158/1078-0432.CCR-19-1089

$29 \mathrm{Xu} \mathrm{Y}$ and Villalona-Calero MA: Irinotecan: mechanisms of tumor resistance and novel strategies for modulating its activity. Ann Oncol 13(12): 1841-1851, 2002. PMID: 12453851. DOI: 10.1093/annonc/mdf337

30 Wei B, Wang J, Zhang X, Qian Z, Wu J, Sun Y, Han Q, Wan L, Zhu J, Gao Y and Chen X: Combination of histoculture drug response assay and qPCR as an effective method to screen biomarkers for personalized chemotherapy in esophageal cancer. Oncol Lett 14(6): 6915-6922, 2017. PMID: 29163710. DOI: 10.3892/ol.2017.7069

31 Jun E, Park Y, Lee W, Kwon J, Lee S, Kim MB, Lee JS, Song KB, Hwang DW, Lee JH, Hoffman RM and Kim SC: The identification of candidate effective combination regimens for pancreatic cancer using the histoculture drug response assay. Sci Rep 10(1): 12004, 2020. PMID: 32686712. DOI: 10.1038/ s41598-020-68703-x

32 Lee B, Min JA, Nashed A, Lee SO, Yoo JC, Chi SW and Yi GS: A novel mechanism of irinotecan targeting MDM2 and Bcl-xL. Biochem Biophys Res Commun 514(2): 518-523, 2019. PMID: 31056264. DOI: 10.1016/j.bbrc.2019.04.009

33 Humerickhouse R, Lohrbach K, Li L, Bosron WF and Dolan ME: Characterization of CPT-11 hydrolysis by human liver carboxylesterase isoforms hCE-1 and hCE-2. Cancer Res 60(5): 1189-1192, 2000. PMID: 10728672.

34 Yuan SQ, Zhou ZW, Liang YJ, Fu LW, Chen G, Qiu HB and Zhang LY: [Correlation of chemosensitivity tested using histoculture drug response assay to expression of multidrug resistance genes and proteins in colorectal cancer tissues]. $\mathrm{Ai}$ Zheng 28(9): 932-938, 2009. PMID: 19728910. DOI: 10.5732/ cjc.008.10787

35 Inagaki Y, Yoshida Y, Hamasaki Y and Ueki H: Protooncogene (C-Myc) expression in the infiltrating cells of lesional skin from patients with systemic lupus erythematosus. J Invest Dermatol 97(1): 80-84, 1991. PMID: 2056195. DOI: 10.1111/1523-1747. ep12478142 